\title{
CALCYCLIN AS A MARKER OF INTRAHEPATIC BILIARY DUCTS IN TRANSPLANTED LIVERS
}

\author{
Bogdan WOŹNIEWICZ ${ }^{1}$, Jolanta KORdOWSKA ${ }^{2}$, Przemyslaw KLUGE ${ }^{1}$, \\ MONIKA PUZIANOWSKA ${ }^{2}$ AND JAGEK KUŹNICKI ${ }^{2}$ \\ ${ }^{1}$ Child Health Center, 04-736 Warsaw, Poland, ${ }^{2}$ Nencki Institute of Experimental \\ Biology and ${ }^{3}$ Pasteur Str., 02-093 Warsaw, Poland
}

Received for publication March 15, 1993 and in revised form May 6, 1993

\begin{abstract}
Calcyclin-a calcium binding protein that belongs to the $S-100$ protein family-is present at high concentration in fibroblasts and epithelial cells. In normal liver calcyclin antibodies stain biliary epithelium, whereas hepatocytes are always negative. Proliferative, degenerative or atrophic changes occurring in biliary epithelium of 8 children with orthotopic liver transplantation (OLT) were monitored using calcyclin antibodies. The antibodies were found to stain epithelium of biliary ducts and ductuli in normal and pathologically changed livers. Single calcyclin positive hepatocytes (probably representing "prebiliary epithelial cells") could be detected only under pathological conditions.
\end{abstract}

Calcyclin is a calcium binding protein that was originally purified from Ehrlich ascites tumour cells (9, 10). The calcyclin gene was identified and cloned by Calabretta et al. (1), as a gene activated by growth factors and deregulated in acute human myeloid leukemia. Calcyclin belongs to the $\mathrm{S}-100$ protein family $(1,7,12)$ and was found to be expressed in a cell and tissue specific manner $(5,11,13,19-21,23)$. Recently we have found that in human tissues, calcyclin is preferentially expressed in fibroblasts and epithelial cells such as glandular or transitional epithelium, and in epithelium of the intrahepatic bile ducts (13). The level of calcyclin in supernatant liver with an experimentally induced increase of the number of intrahepatic bile ducts was higher than in normal liver (8). Anti-calcyclin immunostaining of epithelial cells of bile ducts in these livers was very strong $(8,13)$. It has been suggested therefore, that we might consider calcyclin as a useful marker of some diseases in which proliferation of some kind of epithelium occurs $(8,13)$.

In transplanted liver, injury of the intrahepatic bile ducts occurring in acute and chronic graft rejection is an important diagnostic factor $(3,4,16,22)$. These changes include infiltration by mononuclear cells, destruction, proliferation and vanishing bile

Address for correspondence: B. Woźniewicz, Professor and Chairman, Department of Pathomorphology, Child Health Center, Al. Dzieci Polskich 20, 04-736 Warsaw, Poland. ducts syndrome (atrophy). Therefore, the identification of bile ducts in portal space of transplanted liver is not easy using hematoxylin/eosin staining $(6,14,15$, $17,18)$. Until now, in doubtful cases cytokeratin antibodies were used, although only some of them (e.g. MNF 116) distinguish hepatocytes from bile duct epithelium.

The aim of this work was to examine if antibodies against calcyclin might be used to detect the intrahepatic bile duct epithelium. The results indicate the possibility to apply anti-calcyclin staining as an additional marker (apart from hematoxylin/eosin and anti-cytokeratin staining) of biliary epithelium.

\section{MATERIALS AND METHODS}

60 human liver biopsies obtained from children (Department of Pathology at Child Health Center in Warsaw) were used for diagnostic purposes. These biopsies arose from 8 transplanted livers in 8 patients. Explant livers from 8 patients and donors' livers from 14 patients were used as control material. The clinical stage of the donors' and transplanted livers were determined by the histological analysis (Hannovers' classification was used) and biochemical follow up. The indication to the transplantation was: in 6 patients-biliary cirrhosis, in 2 patients-cryptogenic cirrhosis.

Human tissue specimens were obtained surgically 
or by biopsy and were fixed in $10 \%$ formalin TBS buffered (TBS- $5 \mathrm{mM}$ Tris-HCl, pH 7.6 and $2 \mathrm{mM}$ phosphate-buffered saline). Paraffin blocks were then cut in $4 \mu \mathrm{m}$ sections, which were melted on the slides covered with poly-L-lysine. Reaction with calcyclin antibodies, reaction with antibodies against cytokeratins (MNF-116, CK-1) and hematoxylin/eosin staining were performed on slices from each biopsy material.

Calcyclin was isolated from mouse Ehrlich ascites tumour cells as described (9). The affinity purified polyclonal antibodies specific to calcyclin were obtained as described earlier $(10,11,21)$.

Immunohistochemical methods

Reaction with affinity purified antibodies against calcyclin was developed using the peroxidase-antiperoxidase (PAP) technique as described previously (13). After deparaffinization, the sections were treated with methanol, including $0.3 \% \mathrm{H}_{2} \mathrm{O}_{2}$, to inactivate endogenous peroxidase and with normal swine serum for $40 \mathrm{~min}$ to remove nonspecific background. Next, the sections were treated with primary antibody (diluted $1 / 40-1 / 50$ in TBS) for $2 \mathrm{hr}$ at room temperature, reacted with swine anti-rabbit IgG (1/40 in TBS) for $30 \mathrm{~min}$ and then treated with PAP complex $(1 / 100$ in TBS) for $30 \mathrm{~min}$. Normal swine serum, swine antirabbit IgG and soluble complex of rabbit PAP were from DAKO, Denmark. Colour reaction was developed with $0.1 \% 3,3^{\prime}$-diaminobenzidine tetrahydrochloride (DAB) with $0.02 \%$ hydrogen peroxide. In some experiments the slides were counterstained with hematoxylin and covered by glycero-gelatin. Control sections were incubated with nonimmune serum at the same dilution as the primary affinity purified antibodies or with TBS and treated as described above with PAP and DAB.

Monoclonal anticytokeratin staining was performed with APAAP procedure (2). Results of the staining are summarized in Table 1 , but the stained slices are not shown. Mouse monoclonal antibody against cytokeratin MNF 116 and CK-1, rabbit anti-mouse IgG and complex of alkaline phosphatase-anti-alkaline phosphatase (APAAP) were from DAKO, Denmark. Endogenous alkaline phosphatase activity of biliary epithelium was quenched by the addition of $5 \mathrm{mM}$ levamisole to the substrate solution.

\section{RESULTS}

\section{Donors' livers}

Donors' livers from 14 patients before perfusion showed calcyclin positive immunoreaction in all biliary ducts. Usually 2-5 ducts and 1 ductule of Hering were stained by calcyclin antibodies in 1 portal space. The same number of ducts was identified in sections of the livers that were stained with hematoxylin-eosin. After perfusion (in "University of Wisconsin" solution), cooling and storage of donors' livers (biopsies were taken between 10 to $18 \mathrm{hr}$ after perfusion) the majority of ducts and ductuli of Hering showed poor, or loss of, calcyclin staining (Table 1). The staining of donors' livers using cytokeratin antibodies (either CK-1 or MNF-116) was not changed as a result of perfusion and storage (Table 1).

Transplanted livers

As early as $12 \mathrm{hr}$ after orthotopic liver transplantation (OLT), reaction with calcyclin antibodies was similar to that observed in livers before the preserva-

TABLE 1. Comparison of calcyclin and cytokeratin immunostaining of hepatocytes and epithelium of biliary ducts in normal liver donors before $(A)$, and after $(B)$ preservation procedure

\begin{tabular}{|c|c|c|c|c|}
\hline \multirow{2}{*}{$\begin{array}{l}\text { Antibodies } \\
\text { against }\end{array}$} & \multicolumn{2}{|c|}{ Hepatocytes } & \multicolumn{2}{|c|}{$\begin{array}{l}\text { Ducts \& ductuli (Hering) } \\
\text { (per one portal space) }\end{array}$} \\
\hline & $\mathrm{A}$ & B & A & B \\
\hline Calcyclin & none & none & $\begin{array}{c}\text { all } \\
\text { (e.g. } 3.3 \pm 1.1)\end{array}$ & none \\
\hline $\begin{array}{l}\text { Cytokeratins: } \\
\text {-CK-1 }\end{array}$ & all & all & $\begin{array}{c}\text { all } \\
\text { (e.g. } 3.6 \pm 0.5)\end{array}$ & $\begin{array}{c}\text { all } \\
\text { (e.g. } 3.6 \pm 0.5)\end{array}$ \\
\hline -MNF 116 & none & none & $\begin{array}{c}\text { all } \\
\text { (e.g. } 3.2 \pm 0.6)\end{array}$ & $\begin{array}{c}\text { all } \\
\text { (e.g. } 3.3 \pm 0.8)\end{array}$ \\
\hline
\end{tabular}

"all" - means, that all observed hepatocytes or biliary ducts were immunopositive. "none" - means, that all observed hepatocytes or biliary ducts were immunonegative. In brackets are examples of numeral data calculated as a middle value of five donor's livers. These data are indicated by Means \pm Standard Deviations for at least 3 independent determinations (in 3 different portal spaces) in the same biopsy. 
tion procedure. All portal ducts and ductuli (Hering) were again calcyclin positive.

Sixty liver biopsies obtained from 8 transplanted livers were analysed using calcyclin antibodies. At least three different portal spaces from one biopsy material were analysed. Anti-calcyclin staining revealed the presence of normal biliary ducts and ductuli as well as several abnormalities in their number and staining. Portal ducts with regular shape, lumen and basal membrane were considered to be natural ones (normal).

Fig. 1A shows the staining of portal ducts and Hering ductuli in healthy transplanted liver. In biopsy material taken from patients with excellent clinical course all ducts and ductuli were calcyclin positive.

One of the abnormal phenomenons observed in some transplanted livers was the proliferation of biliary ductuli. These new formed ductuli were also calcyclin positive (Fig. 1B). Proliferated ductuli were seen one week after OLT and their number increased in subsequent biopsies.

Calcyclin antibodies stained different types of abnormal ductuli: branching, cyst-like and atrophic (Fig. 1C). In routine hematoxylin/eosin staining the atrophic ducts were usually poorly visible. In contrast, they were stained well with calcyclin antibodies. Moreover, using the reaction with calcyclin antibodies it was possible to visualize rudimentary ductuli, degeneration of biliary ducts and ductular atrophy (Fig. 1D).

Another pathological phenomenon was the exhibition of different patterns of biliary epithelium staining in one portal space or in adjoining spaces. In addition to the typical ones (all calcyclin positive ducts), there were portal spaces in which both calcyclin positive and calcyclin negative ducts were seen. It was also found that whereas one portal space had normal ducts, another one in the same biopsy material had abnormal ductuli. Fig. 2A shows several ducts that were stained differently with calcyclin antibodies: one in which all cells contain calcyclin and another one in which only one cell is calcyclin positive.
Another abnormal phenomenon was the appearance of single calcyclin positive hepatocytes, or their aggregates. This suggests that liver cells that are usually calcyclin negative convert themselves to calcyclin positive cells under some pathological conditions (Fig. 2B). Probably they represent the early phase in the formation of new epithelium of proliferating ductuli, which we call "prebiliary epithelium". It should be stressed that calcyclin positive hepatocytes were only seen under pathological conditions, such as bile ducts proliferation and failure of allografts, but were not seen in patients with excellent clinical course.

\section{Is calcyclin staining useful in prognosis of OLT patients?}

Table 2 contains the summary of data obtained from 8 patients with transplanted livers. Three patients (KA, PJ, ZM) had an excellent clinical course and biochemical follow-up during the observation period: 15, 14 and 18 months, respectively. Their livers contained normal, unchanged portal spaces with regular ducts. The biopsies taken during the screening period had revealed that all ducts in portal spaces were normal and calcyclin positive. Neither proliferation of ductuli, nor transformation of calcyclin negative hepatocytes into calcyclin positive cells was observed. The lack of changes in calcyclin staining correlates well with the clinical status of those patients. It is important to point out that the number of biliary ducts and ductuli of Hering was low (similar to normal healthy liver), and when all biliary ducts were calcyclin positive-the clinical course of the patient was excellent.

Three other patients described (Table 2, patients TM, MV, WA) had satisfactory graft function, but had complicated clinical course: repeated episodes of acute rejection, presence of chronic rejection or extrahepatic biliary obstruction (for instance-patient TM, Table 2). In the livers of those patients, calcyclin antibodies revealed the structural changes similar to those with fatal clinical course (see below). Various forms of portal spaces were observed: (i) normal space with typical, calcyclin positive ducts, (ii) por-

Figs. 1A-D. Anticalcyclin staining of the biliary ducts in transplanted livers from patients with different clinical course (see Table 2). A. Normal portal duct (pd) and Hering ductuli (Hd) in liver of patient (ZM) with excellent clinical course. $\times 400$ Insert-patient KA B. Proliferation of biliary ducts (bd) in livers from two patients: top-patient MJ; bottom-patient TM; hepatocytes (h) are calcyclin negative; rag. $\quad \times 320$ C. Cyst-like (cl) and atrophic (a) ducts (patient WA). $\times 400 \quad$ D. Degeneration of biliary ducts, calcyclin positive bile deposits (b) (patient BM). $\quad \times 400$

FIGs. 2A-D. Anti-calcyclin staining in transplanted liver and explant with cirrhosis biliaris (see Table 2).

A. Different staining of biliary epithelial cells: calcyclin positive cell ("+"), calcyclin negative cell (" - ), duct containing all calcyclin positive cells (d) (patient TM). $\times 400$ B. Single calcyclin positive hepatocytes (ph) and their aggregates (pa) between calcyclin negative hepatocytes, (patient MV). $\times 400$ C, D. Proliferation of calcyclin positive biliary ducts (bd) in explant liver with biliary cirrhosis; hepatocytes $(\mathrm{h})$ are negative. C. $\times 125, \mathrm{D} . \quad \times 400$ 

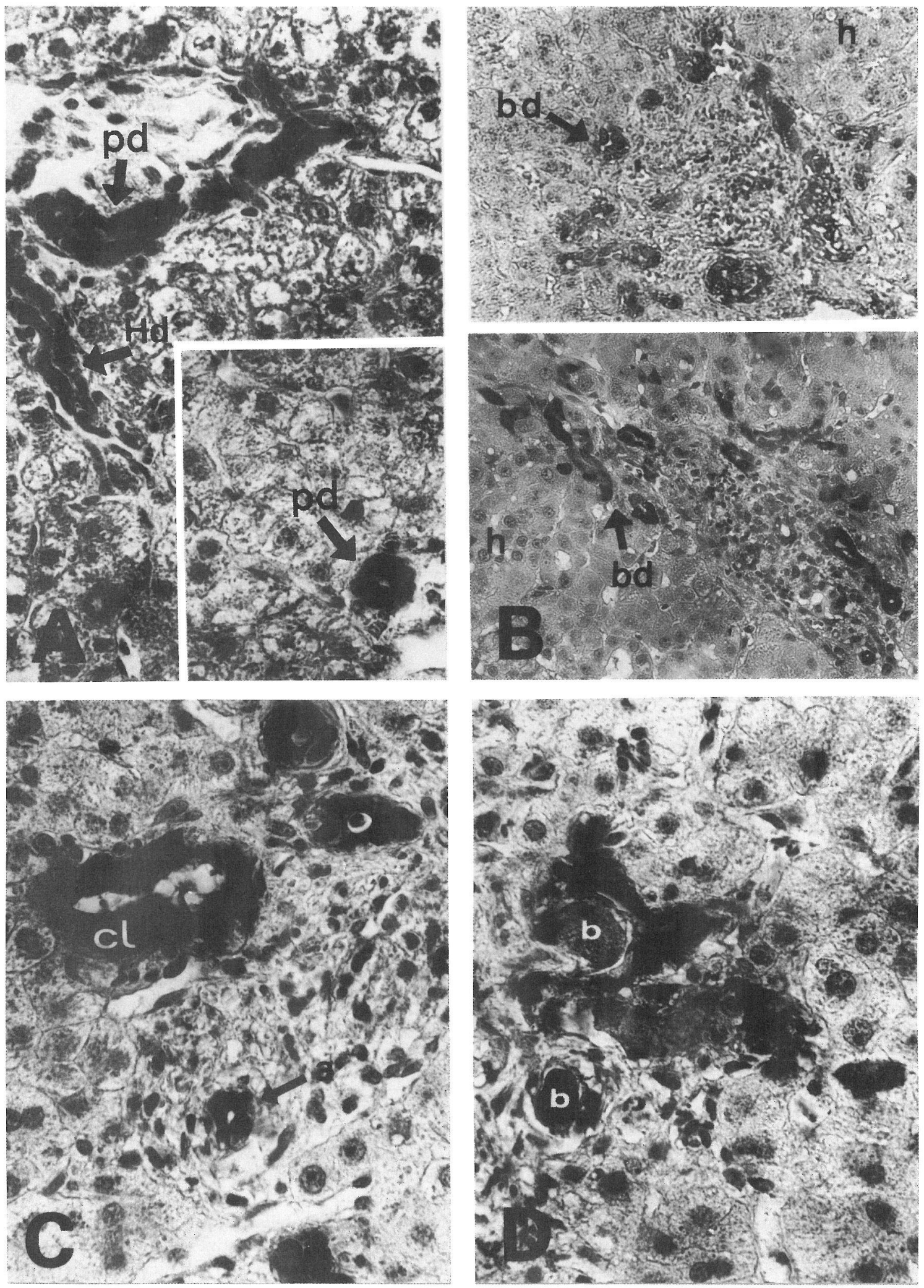


tal space with proliferation of biliary ducts, and (iii) portal space without any calcyclin positive ducts. Although clinical course of those patients was satisfactory, the changes in their livers, that were revealed by calcyclin staining, seem to be prognostically unfavourable.

Livers of two patients who died 3 months after transplantation (Table 2, patients $\mathrm{MJ}, \mathrm{BM}$ ) had two kinds of pathological changes. Biopsies taken from the liver of the patient (Table 2, patient MJ) who died due to chronic rejection of the graft and HCV infection revealed increased number of ducts and ductuli. Only half of them was calcyclin positive. Biopsies of the transplanted liver taken from the patient who died due to generalized CMV infection (Table 2, patient $\mathrm{BM}$ ) showed the destruction of ducts and ductuli.

\section{Explants with biliary cirrhosis}

In the explant of recipient liver with biliary cirrhosis, the reaction with calcyclin antibodies showed high proliferation of the ductuli in peripheral area of the lobule and in fibrotic portal spaces (Figs. 2C, D). The increase in number of biliary ducts in biopsies taken from the same patient with 10 to 14 days of interval was observed. Normal ductuli and abnormal proliferating ductuli were calcyclin positive. Moreover, the transformation of hepatocytes to "prebiliary epithelium" was detected in this liver due to the reaction with calcyclin antibodies. There were single cells and their aggregates looking like new formed ductuli.

\section{DISCUSSION}

We demonstrated in our previous paper that calcyclin is preferentially expressed in fibroblasts and epithelial cells of normal human organs (13). In healthy human liver, positive immunoreactivity against calcyclin was present only in epithelial cells of biliary ducts (13). In the present study we revealed that affinity purified antibody against calcyclin stains epithelial cells of biliary ducts not only in normal liver, but also in the pathologically changed liver.

In the present study we analysed donors' livers, liver explants and biopsy material taken from 8 children with orthotopic liver transplantation. We have shown that calcyclin can be a marker in monitoring biliary epithelium morphology in liver allografts. Calcyclin antibodies stained not only normal biliary ducts in healthy livers (donors' and allograft with excellent course), but also different types of proliferating, atrophic, rudimentary ductuli, etc., in livers that ex-

TABLE 2. Calcyclin positive (cacy+) ducts and ductuli in the last biopsy after OLT

\begin{tabular}{|c|c|c|c|c|c|c|}
\hline \multirow{2}{*}{\multicolumn{2}{|c|}{$\begin{array}{l}\text { Patient } \\
\text { (years } \\
\text { \& sex) }\end{array}$}} & \multirow{3}{*}{$\begin{array}{c}\begin{array}{c}\text { Clinical } \\
\text { course }\end{array} \\
\text { Excellent }\end{array}$} & \multirow{3}{*}{$\begin{array}{c}\begin{array}{c}\text { Interval } \\
\text { after OLT } \\
\text { (months) }\end{array} \\
15\end{array}$} & \multirow{3}{*}{$\begin{array}{c}\begin{array}{c}\text { cacy }+ \\
\text { hepatocytes }\end{array} \\
-\end{array}$} & \multicolumn{2}{|c|}{$\begin{array}{c}\text { Ducts and ductuli } \\
\text { per one portal space }\end{array}$} \\
\hline & & & & & \multirow{2}{*}{$\begin{array}{c}\text { Total } \\
3.6 \pm 0.5 \\
(3-4)\end{array}$} & \multirow{2}{*}{$\begin{array}{c}\text { cacy+ } \\
3.6 \pm 0.5 \\
(3-4)\end{array}$} \\
\hline $\mathrm{KA}$ & $3 \mathrm{M}$ & & & & & \\
\hline PJ & $4 \mathrm{M}$ & Excellent & 14 & - & $\begin{array}{c}5.0 \pm 1.0 \\
(4-6)\end{array}$ & $\begin{array}{c}5.0 \pm 1.0 \\
(4-6)\end{array}$ \\
\hline $\mathrm{ZM}$ & $2 F$ & Excellent & 18 & - & $\begin{array}{c}5.0 \pm 1.0 \\
(4-6)\end{array}$ & $\begin{array}{c}5.0 \pm 1.0 \\
(4-6)\end{array}$ \\
\hline MV & $17 F$ & Satisfactory & 10 & - & $\begin{array}{c}7.0 \pm 1.7 \\
(5-8)\end{array}$ & $\begin{array}{c}5.3 \pm 0.6 \\
(5-6)\end{array}$ \\
\hline $\mathrm{TM}$ & $1 \mathrm{~F}$ & Satisfactory & 6 & - & $\begin{array}{r}12.0 \pm 3.5 \\
(10-16)\end{array}$ & $\begin{array}{r}7.3 \pm 2.5 \\
(5-10)\end{array}$ \\
\hline WA & $4 F$ & Satisfactory & 3 & + & $\begin{array}{r}17.0 \pm 2.0 \\
(15-19)\end{array}$ & $\begin{array}{r}8.7 \pm 1.2 \\
(8-10)\end{array}$ \\
\hline $\mathrm{MJ}$ & $8 \mathrm{~F}$ & $\mathrm{HCV}$, died & 2 & + & $\begin{array}{r}12.7 \pm 5.5 \\
(9-19)\end{array}$ & $\begin{array}{c}6.3 \pm 2.3 \\
(5-9)\end{array}$ \\
\hline $\mathrm{BM}$ & $3 \mathrm{M}$ & CMV, died & 2 & + & $2 \mathrm{~d}$ & $1 \mathrm{~d}$ \\
\hline
\end{tabular}

Data are indicated by Means \pm Standard Deviations for 3 independent determinations (in 3 different portal spaces) in the same biopsy.

In brackets are indicated minimal and maximal numbers (range) of counted ducts in one portal space.

cacy + : calcyclin positive cells or ducts, HCV: herpes $\mathrm{C}$ virus, GMV: cytomegalovirus, $\mathrm{d}$ : destruction of the tissue. 
hibit pathological changes.

Our earlier study revealed that when the number of calcyclin positive cells in the diseased liver increases, we can see an increase of the calcyclin level even in supernatant livers $(8,13)$. In hypertrophied hearts of the cats was seen an increased number of calcyclin-positive cells. In parallel we also observed an increased level of calcyclin mRNA (8).

In biopsies of human liver with cirrhosis biliar (13, present study), an epithelium of intrahepatic biliary ducts was visible due to the staining with calcyclin antibodies. In rat liver (8), in which an increase in the number of biliary ducts was experimentaly induced, the increased number of calcyclin positive cells was detected not only by immunohistochemistry, but also by Western blotting and ELISA (all methods applied calcyclin specific antibodies). This data indicates that calcyclin amounts depend on the physiological state of the investigated heart or liver. So, these changes of calcyclin (on the protein or mRNA level) might correlate with the state of the organ. All these observations led us to expect that calcyclin staining might be useful in monitoring changes of biliary ducts occurring in transplanted liver.

Both the proliferation and atrophy of biliary ducts occurring during acute or chronic rejection episodes could be detected using calcyclin staining. Therefore, this staining is helpful in visualisation of changes of biliary epithelium. In livers with biliary cirrhosis, high rate of ductuli proliferation is observed. The pattern of anti-calcyclin staining of biliary ducts in this kind of liver disease is much stronger than the anticytokeratin staining. Also, some hepatocytes were stained with calcyclin antibodies. We suggest that these single cells represent the early phase of formation ductular proliferation. It is possible that new biliary ductuli are formed from either existing biliary ductuli or undifferentiated precursors (might be from dedifferentiated, calcyclin-positive hepatocytes).

Distribution of calcyclin in sections obtained from explanted livers with postinflammatory cirrhosis was completely different from that observed in sections of livers with biliary cirrhosis. No significant proliferation of biliary ducts occurred.

At present, cytokeratin antibodies are used routinely to recognize pathological changes of intrahepatic biliary ducts in liver. Calcyclin antibodies seem to give a similar pattern of staining to anticytokeratin staining, but not identical. For instance, calcyclin antibodies stain hepatocytes transformed into cells that probably represent the precursors of prebiliary epithelium, but cytokeratin antibodies do not stain them. Moreover, calcyclin antibodies detect the changes in biliary epithelium due to the preservation, perfusion and cooling of liver, whereas cytokeratin antibodies don't. During the preservation procedure, calcyclin antigen lost its immunoreactivity (probably protein was washed out of the cell during perfusion or some components of the perfusing fluid decreased calcyclin immunoreactivity).

The results described in this paper suggest that calcyclin is a marker of normal and pathological biliary epithelium. Whether or not calcyclin staining may be useful in making a prognosis of liver allograft remains to be established by more systematic studies. We undoubtedly think that correlations exist between expression of calcyclin immunoreactivity and cellular morphology and function; Similar to the rejected liver pattern of anti-calcyclin staining we observed in normal and pathologically changed human kidney (13). These were strong immunoreactivity in epithelial cells of some tubules, whereas epithelial cells of other tubules were negative. It suggests a physiological correlation between the presence of calcyclin in the cell and the state of the cell.

The preliminary data of this work supports the hypothesis that anti-calcyclin staining might be accessory in detecting the pathological changes (hepatocellular damage and proliferation of biliary ducts) during the complicated or fatal clinical course of transplanted livers.

\section{ACKNOWLEDGMENTS}

This work was supported by grants from the Polish State Committee for Scientific Research (No. 412409101) and by grant to J. Kuźnicki from UNESCO (contract no SC/RP 201313.1). We thank Ms. Barbara Zarzycka for typing the manuscript.

\section{REFERENGES}

1. Calabretta, B., Battini, R., Kaczmarek, L., de Riel, J. K. and Baserga, R.: Molecular cloning of the c-DNA for a growth factor-inducible gene with strong homology to S100, a calcium-binding protein. J. Biol. Chem. 261; 12628-12632, 1986.

2. Cordell, J. L., Falini, B., Erber, W. N., Ghodk, A. K., Abdulaziz, Z., MacDonald, S., Pulford, K. A. F., Stein, H. and Mason, D. Y.: Immunoenzymatic labeling of monoclonal antibodies using immune complexes of alkaline phosphatase and monoclonal anti-alkaline phosphatase (APAAP complexes). J. Histochem. Cytochem. 32; 219-229, 1984.

3. Demetrias, A. J., Jaffe, R. and Starzl, E.: A review of 
adult and pediatric post-transplantant liver pathology. In "Pathology Annual", ed. by P. P. Rosen and R. E. Fechner, San Mateo, California, Appleton and Lange Norwalk, 1987, part 2, vol. 22, pp. 347-386.

4. Fennel, R. H.: Ductular damage in liver transplant rejection; its similarity to that of primary biliary cirrhosis and graft-versus-host disease. Pathol. Annu. 16; 289-294, 1981.

5. Gong, Y., Alkhalaf, B., Murphy, L. J. and Murphy, L. C.: Differential effects of phorbol esters on proliferation and calcyclin expression in human endometrial carcinoma cells. Cell Growth Differ. 3; 11; 847-853, 1992.

6. Hubscher, S. G.: Histological findings in liver allograft rejection-new insights into the pathogenesis of hepatocellular damage in liver allografts. Histopathology 18; 377-382, 1991.

7. Kligman, D. and Hilt, D. C.: The S-100 protein family. Trends Biochem. Sci. 13; 437-443, 1988.

8. Kordowska, J., Apel, A., Brand, I. A., Pollack, P. S., Goldman, B. and Kuźnicki, J.: Distribution and level of calcyclin in normal rat tissues and in two experimentally induced diseases: liver cirrhosis biliar and heart hypertrophy. (submitted).

9. Kuźnicki, J. and Filipek, A.: Purification and properties of a novel $\mathrm{Ca}^{2+}$-binding protein $(10.5 \mathrm{kDa})$ from Ehrlichascites-tumour cells. Biochem. J. 247; 663-667, 1987.

10. Kuźnicki, J., Filipek, A., Hunziker, P. E., Huber, S. and Heizmann, C. W.: Calcium binding protein from mouse Ehrlich ascites-tumour cells is homologous to human calcylin. Biochem. J. 263; 951-956, 1989.

11. Kuźnicki, J., Filipek, A., Heimann, P., Kaczmarek, L. and Kamiñska, B.: Tissue specific distribution of calcyclin-10.5 $\mathrm{kDa} \mathrm{Ca}^{2+}$-binding protein. FEBS Lett. 254; 141-144, 1989.

12. Kuźnicki, J.: In “Novel Calcium-Binding Proteins”, ed. by C. W. Heizmann, Springer-Verlag, Berlin, Heidelberg, 1991, pp. 157-167.

13. Kuźnicki, J., Kordowska, J., Puzianowska, M. and Woźniewicz, B.: Calcyclin-as a marker of human epithelial cells and fibroblasts. Exp. Cell Res. 200; 425430,1992

14. Ludwig, J., Wiesner, R. H., Batts, K. P., Perkins, J. D. and Krom, R. A. F.: The acute vanishing bile duct syn- drome (acute irreversible rejection) after orthotopic liver transplantation. Hepatology 7; 476-483, 1987.

15. Nakanuma, Y. and Ohta, G.: Histometric and serial section observations of the intrahepatic bile ducts in primary biliary cirrhosis. Gastroenterology 76; 1326-1332, 1979.

16. Oguma, S., Belle, S., Starzl, E. and Demetris, J.: A histometric analysis of chronically rejected liver allografts; insight into mechanism of bile duct loss; direct immunologic and ischemic factors. Hepatology 9; 204-209, 1989.

17. Raweily, A., Gibson, A. A. M. and Burt, A. D.: Abnormalities of intrahepatic bile ducts in extrahepatic biliary atresia. Histopathology 17; 521-527, 1990.

18. Takemura, M., Oguma, S., Mori, S., Ishii, M., Starzl, T. E., Demetris, A. J. and Takahashi, T.: Prebiliary vascular diseases in rejected livers; computer-aided threedimensional reconstruction and morphometry. Transplantation Proc. 23; 1409-1412, 1991.

19. Tokumitsu, H., Kobayashi, R. and Hidaka, H.: A calcium-binding protein from rabbit lung cytosol identified as the product of growth-regulated gene (2A9) and its binding proteins. Arch. Biochem. Biophys. 288; 202-207, 1991.

20. Tokumitsu, H., Mizutani, A., Minami, H., Kobayashi, R. and Hidaka, H.: A calcyclin-associated protein is a newly identified member of the $\mathrm{Ca}^{2+}$ /phospholipid-binding proteins, annexin family. J. Biol. Chem. 267; 89198924, 1992.

21. Tonini, G. P., Antonella, C., Cara, A. and DiMartino, D. D.: Inducible expression of calcyclin, a gene with strong homology to S-100 protein during neuroblastoma cell differentiation and its prevalent expression in Schwann-like cell lines. Cancer Res. 51; 1733-1737, 1991.

22. Vierling, J. M. and Fennel, R. H.: Histopathology of early and late human hepatic rejection evidence of progressive destruction of interlobular bile ducts. Hepatology 5; 1076-1082, 1985.

23. Weterman, M. A.J., Stoopen, G. M., van Muijen, D. N. P., Kuźnicki, J., Ruiter, D. J. and Bloemers, H. P. J.: Expression of calcyclin in human melanoma cell lines correlates with metastatic behavior in nude mice. Cancer Res. 52; 1291-1296, 1992. 